\title{
Leydig cell-derived heme oxygenase-1 regulates apoptosis of premeiotic germ cells in response to stress
}

\author{
Nobuaki Ozawa, ${ }^{1}$ Nobuhito Goda, ${ }^{2}$ Nobuya Makino, ${ }^{2}$ Tokio Yamaguchi, ${ }^{3}$ \\ Yasunori Yoshimura, ${ }^{1}$ and Makoto Suematsu ${ }^{2}$ \\ ${ }^{1}$ Department of Obstetrics and Gynecology, School of Medicine, and \\ ${ }^{2}$ Department of Biochemistry and Integrative Medical Biology, Keio University, Tokyo, Japan \\ ${ }^{3}$ Department of Molecular Genetics and Biochemistry, Tokyo Medical and Dental University, Tokyo, Japan \\ Address correspondence to: Makoto Suematsu, Department of Biochemistry and Integrative Medical Biology, \\ School of Medicine, Keio University, 35 Shinanomachi, Shinjuku-ku, Tokyo 160-8582, Japan. \\ Phone: 81-3-5363-3753; Fax: 81-3-3358-8138; E-mail: msuem@sc.itc.keio.ac.jp.
}

Received for publication May 3, 2001, and accepted in revised form January 7, 2002.

\begin{abstract}
Stress-induced downregulation of spermatogenesis remains poorly understood. This study examined the induction of heme oxygenase-1 (HO-1), a carbon monoxide-generating inducible enzyme, in modulation of spermatogenesis. Rats were exposed to cadmium chloride $\left(\mathrm{CdCl}_{2}\right)$, a stressor causing oligozoospermia, and $\mathrm{HO}-1$-induction was monitored by following $\mathrm{HO}$ isozyme expression. $\mathrm{CdCl}_{2}$-treated testes increased HO-1 activity and suppressed microsomal cytochromes $\mathrm{P} 450$, which are required for steroidogenesis. $\mathrm{CdCl}_{2}$-elicited $\mathrm{HO}-1$ occurred mostly in Leydig cells and coincided with $\mathrm{CO}$ generation, as judged by bilirubin-IX $\alpha$ immunoreactivity. Under these circumstances, germ cells in peripheral regions of seminiferous tubules exhibited apoptosis; laser flow cytometry revealed that these apoptotic cells involve diploid and tetraploid germ cells, suggesting involvement of spermatogonia and primary spermatocytes in $\mathrm{CdCl}_{2}$-elicited apoptosis. Pretreatment with zinc protoporphyrin-IX, an $\mathrm{HO}$ inhibitor, but not copper protoporphyrin-IX, which does not block the enzyme, attenuated the $\mathrm{CdCl}_{2}$ induced apoptosis. Such antiapoptotic effects of zinc protoporphyrin-IX were repressed by supplementation of dichloromethane, a CO donor. Upon $\mathrm{CdCl}_{2}$-treatment, both Sertoli cells and the germ cells upregulated Fas ligand; this event was also suppressed by zinc protoporphyrin-IX and restored by dichloromethane. Thus, Leydig cells appear to use HO-1-derived CO to trigger apoptosis of premeiotic germ cells and thereby modulate spermatogenesis under conditions of stress.
\end{abstract}

J. Clin. Invest. 109:457-467 (2002). DOI:10.1172/JCI200213190.

\section{Introduction}

Testes execute spermatogenesis and steroidogenesis. These two events occur in distinct compartments of the organ, seminiferous tubules and the interstitial space, respectively (1). Functional integrity of both compartments has thus been considered necessary to maintain quantity and quality of the sperm production. Leydig cells constitute a majority of interstitial cells generating testosterone for spermatogenesis through cytochromes P450 reactions (1). The cells exposed to luteinizing hormone use cholesterol to generate pregnenolone through the cholesterol side-chain cleavage enzyme (cytochrome P450scc) in mitochondria. Pregnenolone is converted in endoplasmic reticulum to testosterone through other P450 enzymes such as $17 \alpha$-hydroxylase.

A variety of stressors have been shown to inhibit spermatogenesis: hyperthermia, microorganisms, exposure to heavy metals, and environmental hormones are involved in such stressors (2). Recent studies revealed that mechanisms for decreased population of germ cells involve apoptosis $(3,4)$. The stress-inducible reduction of a quantity of cells through apoptosis results in testicular atrophy, often leading to irreversible pathologic changes. Considering the necessity of cytochromes P450 in maintaining steroidogenesis and spermatogenesis, it could be hypothesized that regulatory mechanisms for the reaction of the monooxygenases in Leydig cells and their functional link to germ cell apoptosis play crucial roles in controlling spermatogenesis. However, such mechanisms involved in Leydig cells for regulation of spermatogenesis have not been fully investigated. This study examined roles of heme oxygenase-1 (HO-1) in Leydig cells for such a quality-controlling mechanism under stress conditions. HO- 1 is the stress-inducible $\mathrm{HO}$ isozyme generating biliverdin-IX $\alpha$, divalent iron, and carbon monoxide (CO) through oxidative cleavage of protoheme-IX, the prosthetic group of cytochromes P450 (5). The testis is characterized as one of the organs with high activity of $\mathrm{HO}$, the majority of which has been thought to derive from the constitutive isozyme HO-2 (6). We herein tested effects of cadmium chloride $\left(\mathrm{CdCl}_{2}\right)$, a heavy metal stressor inducing oligozoospermia upon overdose (7), on activities of these $\mathrm{HO}$ isozymes and microsomal P450 cytochromes and examined their functional link to apoptosis of testicular germ cells. Current results suggest that Leydig cells serve as a metal stress sensor that primarily induces HO-1 and causes germ cell apoptosis through mechanisms 
involving CO. Furthermore, such CO-mediated apoptotic processes appear to contribute to a quality control of spermatogenesis under stress conditions.

\section{Methods}

Experimental protocols. The present protocols for animal experiments were approved by Institutional Guidelines in Keio University School of Medicine. Male Wistar rats (280 to $320 \mathrm{~g}$ ) obtained from Nippon Bio-Material Inc. (Tokyo, Japan) were allowed free access to laboratory chow and tap water. The rats were treated with a subcutaneous injection of $\mathrm{CdCl}_{2}$ at a dose of 10 or $20 \mu \mathrm{mol} / \mathrm{kg}$ under ether anesthesia. As shown later in Results, 20 $\mu \mathrm{mol} / \mathrm{kg}$ was the minimal dose to cause notable apoptosis at 12 hours after administration. At greater doses of $\mathrm{CdCl}_{2}$, testes were exposed to remarkable edema and/or hemorrhagic changes (data not shown). Thus, the dose of $20 \mu \mathrm{mol} / \mathrm{kg}$ was used throughout the experiments, unless otherwise mentioned. With varied lengths of time after the $\mathrm{CdCl}_{2}$ administration, testes were removed to collect samples for determination of enzyme activities and immunohistochemistry. Rats in different groups were pretreated with an intraperitoneal injection of zinc protoporphyrin-IX ( $\mathrm{ZnPP})$, a potent $\mathrm{HO}$ inhibitor, or copper protoporphyrin-IX (CuPP), which did not block the enzyme activity, at a dose of 40 $\mathrm{mg} / \mathrm{kg} 4$ hours prior to $\mathrm{CdCl}_{2}$ administration. When necessary, dichloromethane was also given intraperitoneally at a dose of $6 \mathrm{mmol} / \mathrm{kg}$ simultaneously with an injection of $\mathrm{CdCl}_{2}$, and the same dose of the reagent was administered again 6 hours later. Dichloromethane is converted to $\mathrm{CO}$ in vivo through the reaction of $\mathrm{P} 450$ cytochromes $(8,9)$. We examined temporal changes in percentages of carboxyhemoglobin $(\mathrm{HbCO})$ contents in venous blood samples collected from rats undergoing the current protocols for the dichloromethane administration according to the previous method (8). The testes removed 12 hours after the $\mathrm{CdCl}_{2}$ administration was used to determine contents of microsomal P450 cytochromes and to examine apoptosis. Dispersed testicular cells, including germ cells, obtained from control and $\mathrm{CdCl}_{2}$-treated rats were used to measure DNA contents by flow cytometry (10).

$\mathrm{HO}$ activities in testicular microsomes. Microsomal $\mathrm{HO}$ activities were determined by measuring formation of bilirubin as described previously (11). To determine the HO-1-specific activity, we used an anti-rat HO-1 mAb GTS-3 prepared and purified in our laboratory. When added in cell lysates, it blocks the HO-1 enzyme activity with its relatively low dose versus another anti-rat HO-1 mAb GTS-1 (12). Such HO-1-specific inhibitory effects of GTS-3 were shown (see Results) in experiments using lysates collected from the rat $\mathrm{HO}-1-$ or HO-2-overexpressing WR19L cells (12). Accordingly, the HO-1-specific enzyme activity was determined by calculating differences between the values measured in the absence and presence of GTS- 3 at $0.5 \mathrm{mg} / \mathrm{ml}$. The HO-1-independent activity was determined by measuring bilirubin production in the presence of GTS-3.
Immunobistochemistry of $\mathrm{HO}$ isozymes and their specific reaction product bilirubin-IX $\alpha$. Frozen sections were immunostained with anti-rat HO-1 (GTS-1) and HO-2 (GTS-2) $\mathrm{mAb}$ 's through indirect immunoperoxidase methods as described previously (11). In dual-color immunohistochemistry, GTS- 1 was used as the initial primary Ab, while either an anti-rat macrophage mAb KiM2R (BMA Biomedicals AG., Augst, Switzerland) or an anti-Ad4BP polyclonal Ab (a generous gift from Ken-ichirou Morohashi, National Institute for Basic Biology, Okazaki, Japan) was used as a second primary Ab. Ad4BP is a transcriptional factor constitutively expressed in nuclei of steroidogenic cells and serves as a reliable marker to identify Leydig cells and Sertoli cells in testis (13). Microtopographic distribution of HO-derived $\mathrm{CO}$ generation was examined immunohistochemically by an anti-bilirubin-IX $\alpha$ mAb $24 \mathrm{G} 7(14,15)$. Contents of microsomal P450 monooxygenases in testicular tissues were determined as described previously (16).

Analyses of $\mathrm{CdCl}_{2}$-induced apoptosis in testes. Histochemical detection of apoptosis-associated DNA fragmentation in testes was performed by the TUNEL method as described elsewhere (17). To count TUNEL-positive cells in the tissues, more than 200 different tubules (four to five tubules were contained in $1 \mathrm{~mm}^{2}$ ) were observed in different microscopic fields covering approximately a total of $50 \mathrm{~mm}^{2}$ for an individual testis of each animal. Only horizontal sections of testes in which a majority of seminiferous tubules displayed round-shaped patterns were chosen for analyses. Four sets of serial sections with $7-\mu \mathrm{m}$ thickness were collected from different portions of the testis. One of the serial slices was used for TUNEL staining and another was stained with the anti-Ad4BP Ab. TUNEL analyses were performed by examining two indices. First, we established a histogram of the number of TUNEL-positive cells per an individual seminiferous tubule. Secondly, percentages of the number of seminiferous tubules containing TUNEL-positive cells were calculated as an indicator for apoptotic changes; tubules showing TUNEL-associated brown dots were considered positive, irrespective of the number of positive cells per a tubule. We examined effects of $\mathrm{ZnPP}$, an $\mathrm{HO}$ inhibitor, on these indices for apoptosis. Restoration effects of supplementation of dichloromethane, a CO donor, on the apoptotic changes were also examined. Administration of the reagent followed the aforementioned protocols. The experiments for TUNEL analyses were repeated using four to eight separate rats. To normalize differences among the groups in the surface area of seminiferous tubules observed for morphometry of apoptotic cells, the density of Sertoli cells was determined by counting the Ad4BP-positive peritubular cells. The cell number in each group was normalized by the mean value of controls and was expressed as percentage values. Such experiments for counting Sertoli cells were repeated in four to five different rats for each group. Effects of following interventions were also examined in rats treated with 
$\mathrm{CdCl}_{2}$ : testosterone propionate (Sigma Chemical Co., St. Louis, Missouri, USA) at $30 \mathrm{mg} / \mathrm{kg}$ intramuscularly and desferrioxamine mesylate (Sigma Chemical Co.), an iron chelator, at $100 \mathrm{mg} / \mathrm{kg}$ intraperitoneally. These reagents were administered simultaneously with $20 \mu \mathrm{mol} / \mathrm{kg} \mathrm{CdCl}$. We also attempted to investigate if Sertoli cells and/or germ cells change their expression of Fas and Fas ligand (FasL) upon the $\mathrm{CdCl}_{2}$ exposure under circumstances with or without $\mathrm{ZnPP}$ and dichloromethane. To this end, the testicular expression of Fas and FasL was examined immunohistochemically using polyclonal Ab's sc-1023 and sc-834, respectively (Santa Cruz Biotechnology Inc., Santa Cruz, California, USA), according to previous methods (17). As described previously (18), sc-834 recognized an intracellular domain mapping at the terminus of FasL of rat origin and was used to examine its expression through FACS analyses using dispersed testicular cells collected from the experimental groups. In these experiments, cells were suspended in $2 \%$ formaldehyde, treated with saponin, and incubated with the $\mathrm{Ab}$ as described elsewhere (18).

Analyses of DNA contents in testicular germ cells. Heterogeneity in DNA contents among testicular germ cells was examined by propidium iodide-associated (PI-associated) fluorescence flow cytometry (10). This procedure allowed us to distinguish germ cells with different phases of meiosis by judging DNA contents; haploid (spermatids and spermatozoa), diploid (resting spermatogonia, secondary spermatocytes, and resting nongerminal cells), and tetraploid (primary spermatocytes and spermatogonia in $\mathrm{G} 2$ and $\mathrm{M}$ phases) cells constitute a series of three histograms with the specific ratio of 1:2:4 in their DNA contents, respectively. Under normal conditions, these three histograms were characterized by their peaks with small SDs, indicating homogeneous DNA contents among individual cells with the same differentiation phase. Such an integrity of DNA contents has been reported to be disrupted through multiple mechanisms involving DNA fragmentation by apoptosis, mechanical or inflammatory injury, and aneuploidy in the cells $(19,20)$. To examine quantitatively such a disruption of DNA contents in germ cells, we calculated the values of coefficient of variation $(\mathrm{CV})$ according to the formula shown in the previous studies: $\mathrm{CV}=100 \times \mathrm{SD} /$ peak channel of the histogram (\%). When necessary, two-color analysis was carried out by flow cytometry using dispersed cells stained with GTS-2 and PI. We also examined if the presence of $\mathrm{CdCl}_{2}$ might affect the quality of PI staining; so far, as determined in a range between $1 \mathrm{nM}$ and $100 \mu \mathrm{M}$, $\mathrm{CdCl}_{2}$ did not alter the PI labeling in germ cells in vitro. Data in the present study were expressed as mean plus or minus standard error of measurements. Differences in statistical significance among groups were analyzed by one-way ANOVA combined with Fisher's-type multiple comparison test. $P$ values less than 0.05 were considered statistically significant.

\section{Results}

$\mathrm{CdCl}_{2}$ administration elicits an induction of HO-1 concurrently with a reduction of HO-2. Figure 1 illustrates timedependent alterations in protein expression of $\mathrm{HO}$ isozymes and their activities in testes of the $\mathrm{CdCl}_{2}$-treated rats. Western blot analyses in Figure 1a showed a slight expression of the HO-1 protein under unstimulated conditions. Upon the $\mathrm{CdCl}_{2}$ administration, the protein increased time dependently and peaked at 24 hours, followed by a decline. On the other hand, HO-2 occurred constitutively in testes as described previously from our and other laboratories $(11,21)$ and exhibited a significant decline upon $\mathrm{CdCl}_{2}$ administration. GTS-3, another $\mathrm{mAb}$ against rat $\mathrm{HO}-1$, turned out to block the HO-1 enzyme activities. As seen in Figure 1b, an addition of the $\mathrm{mAb}$ at $0.5 \mathrm{mg} / \mathrm{ml}$, but not that of the same dose of IgG, to the cell lysate of the HO-1overexpressing WR19L cells attenuated the catalytic activity almost completely. Such inhibitory actions of GTS-3 were not observed in the HO-2-overexpressing WR19L cells. Using this mAb, the HO-1-dependent and -independent fractions of the enzyme activities were determined, and the results are summarized in Figure $1, \mathrm{c}$ and $\mathrm{d}$. The HO-1-specific activity was markedly elevated at 6 hours with a peak at 24 hours and decreased downward to the baseline level. By contrast, the HO-1independent activity was significantly reduced at 24 hours and further decreased time dependently. Considering findings of Western blot analyses, the decrease in the HO-1-independent enzyme activity elicited by $\mathrm{CdCl}_{2}$ appeared to result from that in HO-2. Accordingly, the total $\mathrm{HO}$ activities reached a peak at 12 hours followed by a decrease backward to the baseline level around 24 hours, and then became approximately $25 \%$ of the initial constitutive level at 48 hours.

Leydig cells as a sensor inducing $\mathrm{HO}-1$ upon the $\mathrm{CdCl}_{2}$ administration. Upper and lower panels of Figure 2 illustrate representative pictures of immunohistochemistry showing $\mathrm{CdCl}_{2}$-induced alterations in protein expression of $\mathrm{HO}-1$ and $\mathrm{HO}-2$ in testes, respectively. As seen in Figure 2a, HO-1 was expressed in cells in the interstitial space and those located in peritubular regions characterized by dendritic processes extending toward the tubular center; these cells turned out to be Sertoli cells, as shown later in Figure 3. On the other hand, HO-2 immunoreactivities were mostly observed in a subpopulation of germ cells in the central regions of tubules and their residual bodies, while the expression was evident neither in those distributing in peritubular regions nor in the interstitial space, if any. At 12 hours after the $\mathrm{CdCl}_{2}$ administration, cells in the interstitial space displayed a marked HO-1 expression (Figure 2b, upper) and reached a maximum level at 24 hours, concurrent with marked edematous changes in the interstitium (Figure 2c, upper). During this period, the HO-1 expression in Sertoli cells did not increase greatly. By contrast, HO-2 immunoreactivities in germ cells displayed a time-dependent decline, and concentric 
a

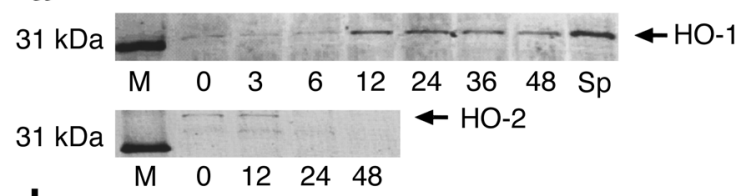

b
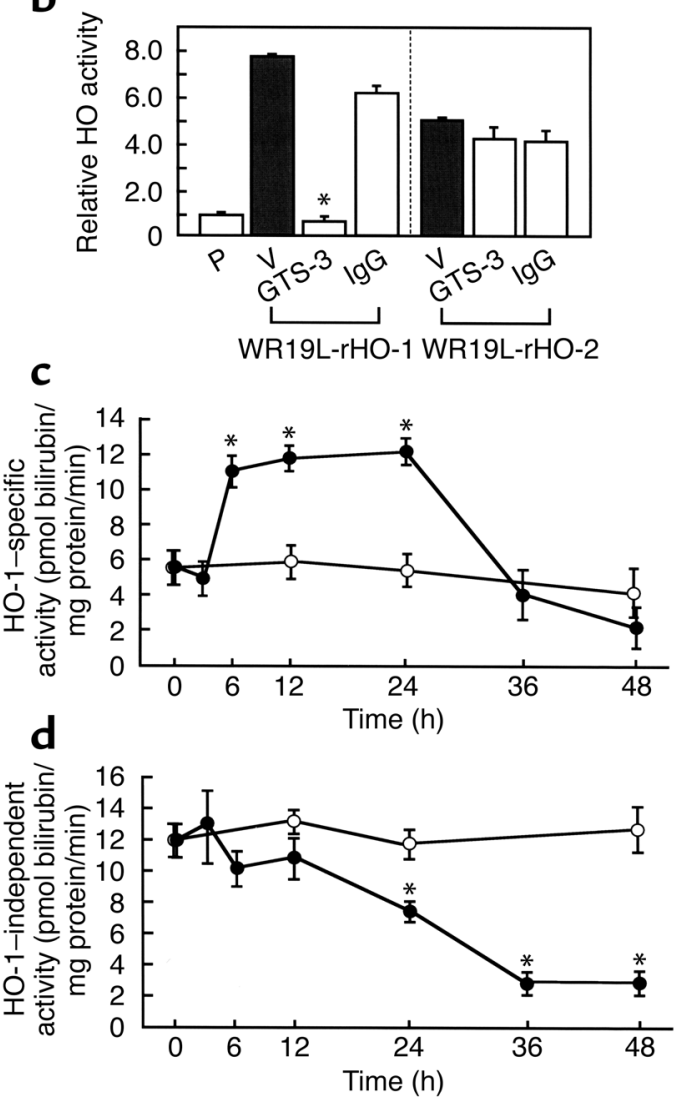

patterns of HO-2-positive cells observed in the control tubules were severely disrupted at 24 hours after the $\mathrm{CdCl}_{2}$ exposure (Figure $2 \mathrm{c}$, lower).

Cell types responsible for the HO- 1 induction were examined through double-color immunohistochemistry (Figure 3). In the $\mathrm{CdCl}_{2}$-untreated controls, the $\mathrm{HO}-1$-positive cells in the peritubular regions (asterisks in Figure 3a) were Sertoli cells that were characterized by nuclear expression of Ad4BP with dendritic processes for docking spindle-shaped germ cells, while those in the interstitial space were Ad4BP negative as shown by arrowheads in Figure $3 \mathrm{~b}$. On the other hand, the Ad4BP-positive cells in the interstitium (asterisks in Figure 3b), that is, Leydig cells, did not display any notable immunoreactivities of HO-1. Double immunostaining with GTS-1 and KiM2R indicated that macrophages

\section{Figure 2}

Immunohistochemistry illustrating temporal alterations in $\mathrm{HO}-1$ and $\mathrm{HO}-2$ protein expression in the $\mathrm{CdCl}_{2}$-treated and control rats. Upper and lower panels denote time-dependent alterations in GTS-1-associated (anti-HO-1) and GTS-2-associated (anti-HO-2) immunoreactivities, respectively. (a) Vehicle-treated control at 12 hours; (b) 12 hours after the $\mathrm{CdCl}_{2}$ treatment; (c) 24 hours after the $\mathrm{CdCl}_{2}$ treatment. Bar, $50 \mu \mathrm{m}$.

\section{Figure 1}

Temporal alterations in expression of $\mathrm{HO}$ isozymes in testicular microsomes of $\mathrm{CdCl}_{2}$-treated and control rats. (a) Western blot analyses of HO- 1 and HO-2 protein expression, using mAb's GTS-1 and GTS-2, as a function of time after the $\mathrm{CdCl}_{2}$ administration. $\mathrm{M}$, molecular markers; Sp, spleen lysate as a positive control for HO-1. (b) Inhibitory action of GTS-3, an anti-rat HO-1 mAb, on $\mathrm{HO}$ activities. WR19LrHO-1, cell transfectant overexpressing rat HO-1; WR19L-rHO-2, cell transfectant overexpressing rat $\mathrm{HO}-2$. $\mathrm{HO}$ activities were expressed as relative values versus parent WR19L cells $(P)$. The $m A b$ or mouse IgG was added at $0.5 \mathrm{mg} / \mathrm{ml}$ to the lysates of the rat HO- 1 or HO-2 cDNAtransfected WR19L cells. V, vehicle. Mean \pm SE of three separate experiments. ${ }^{*} P \leq 0.05$ as compared with the vehicle. (c) Temporal alterations in the HO-1-specific enzyme activity in testicular microsomes collected from the $\mathrm{CdCl}_{2}$-treated (filled circles) and vehicle-treated (open circles) rats. (d) Time course of the HO-1-independent enzyme activities in the same animals. Data in $\mathbf{c}$ and $\mathbf{d}$ represent mean \pm SE of measurements from five to eight testes from different rats. ${ }^{*} P<0.05$ as compared with the data measured at 0 hours.

but not Leydig cells constitute a major component for the interstitial HO-1 expression under unstimulated conditions (Figure 3c). By contrast, in testes of the 12hour $\mathrm{CdCl}_{2}$-treated rats, cells markedly inducing $\mathrm{HO}-1$ were Leydig cells, which were recognized as Ad4BP-positive cells in the interstitium (asterisks in Figure 3d). Another important feature of the $\mathrm{CdCl}_{2}$-exposed testes was apoptosis of germ cells in peritubular regions: This change was characterized by nuclear condensation (arrowheads in Figure 3d) as well as fragmentation of their nuclei (arrowheads in Figure 3e). Cell-phase specificity of such germ cell apoptosis is examined in Results. At the same time, the interstitial macrophages that expressed HO-1 under the unstimulated conditions changed their shapes with pseudopod formation, suggesting activation of phagocytosis (Figure 3f).

Leydig cells primarily display HO-dependent heme degradation upon the $\mathrm{CdCl}_{2}$ administration. Observation that the $\mathrm{CdCl}_{2}$ exposure triggers a marked $\mathrm{HO}-1$ induction

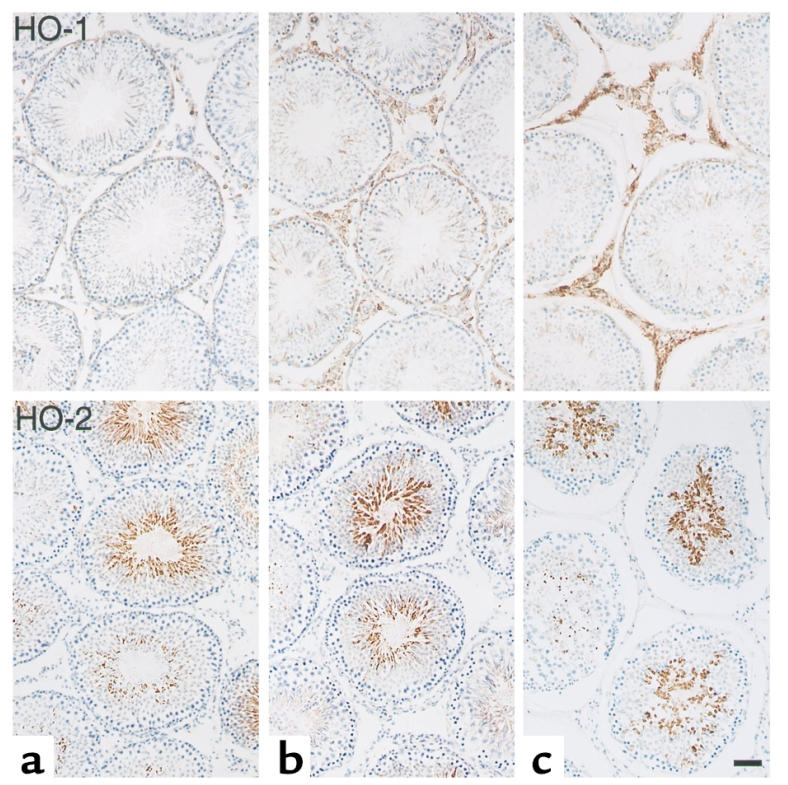



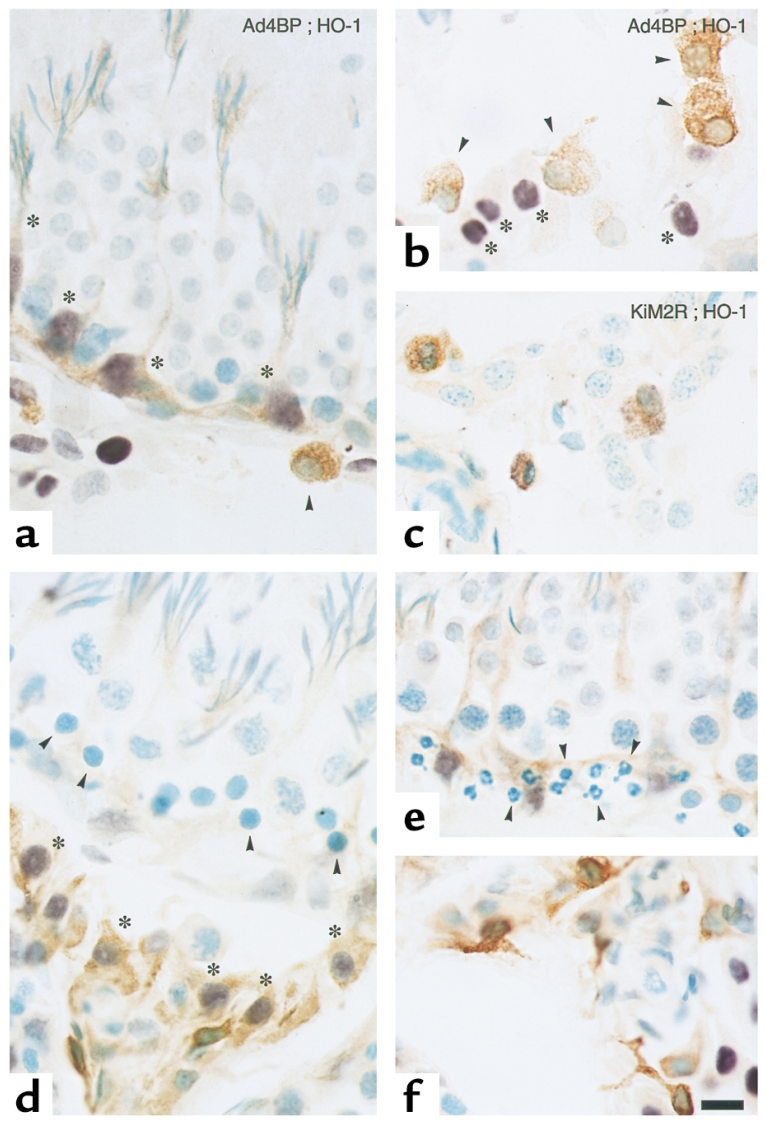

preferentially in Leydig cells led us to examine further whether the enzyme induction could cause actual degradation of heme in situ. Immunohistochemistry using the anti-bilirubin-IX $\alpha \mathrm{mAb} 24 \mathrm{G} 7$ was thus performed (Figure 4). In control rats, bilirubin-IX $\alpha$-associated immunoreactivities were evident in Sertoli cells, as judged by those in their dendritic structures and also faintly noted in interstitial macrophages, while germ cells displayed few reactivities, if any (Figure 4a). On the other hand, the 12-hour $\mathrm{CdCl}_{2}$ treatment elicited a marked elevation of the immunoreactivities in a majority of the interstitial cells (Figure 4b). Doublecolor immunohistochemistry using anti-bilirubinIX $\alpha$ and Ad4BP Ab's confirmed that the interstitial cells responsible for bilirubin generation are Leydig cells (data not shown). These results provided evidence that $\mathrm{CdCl}_{2}$ evokes a bilirubin-IX $\alpha$ overproduction sitespecifically in Leydig cells, while HO-2-expressing

\section{Figure 4}

In situ demonstration of the HO-dependent heme degradation by the anti-bilirubin-IX $\alpha \mathrm{mAb}$-assisted immunohistochemistry in testes of the $\mathrm{CdCl}_{2}$-treated rats. (a) Control. (b) Elevation of bilirubin-IX $\alpha$ generation in the interstitium in the $\mathrm{CdCl}_{2}$-treated rats (arrows). Note marked immunoreactivities in the interstitial cells, while germ cells remained unstained, even after exposure to the metal stressor. (c and d) Effects of pretreatment with ZnPP and CuPP on the $\mathrm{CdCl}_{2}-$ elicited upregulation of bilirubin-IX $\alpha$ generation, respectively. Note that ZnPP but not CuPP attenuated interstitial bilirubin-IX $\alpha$ generation shown in $\mathbf{b}$. Bar, $50 \mu \mathrm{m}$.

\section{Figure 3}

Characterization of cell types expressing $\mathrm{HO}-1$ in testes of the $\mathrm{CdCl}_{2-}$ untreated $(\mathbf{a}-\mathbf{c})$ and -treated $(\mathbf{d}-\mathbf{f})$ rats by double-color immunohistochemistry. ( $\mathbf{a}$ and $\mathbf{b}$ ) Distribution of GTS-1-positive (anti-HO-1positive) cells and its topographic relationship to Ad4BP-positive steroidogenic cells. Arrowheads; macrophages characterized with positive $\mathrm{HO}-1$ immunoreactivities (brown) lacking in nuclear Ad4BP expression. Asterisks indicate Sertoli cells (peritubular cells in a) and Leydig cells (interstitial cells in $\mathbf{b}$ ), which were characterized by the Ad4BP expression (purple). The former cells were also characterized by their dendritic processes for docking spindle-shaped spermatids. (c) Double immunostaining with HO-1 (brown) and KiM2R (purple). Note that in control testes, $\mathrm{HO}-1$ is expressed mostly in the interstitial macrophages, but not in Leydig cells. (d) Distribution of GTS-1 (anti-HO-1) immunoreactivities and its topographic relationship to Ad4BP-positive steroidogenic cells in $\mathrm{CdCl}_{2}$-treated rats. Note that $\mathrm{HO}-1$-associated immunoreactivities (brown) markedly increase in Leydig cells (asterisks, purple nuclei). (e) Nuclear condensation and fragmentation in peritubular germ cells (arrowheads in $\mathbf{d}$ and $\mathbf{e}$ ). ( $\mathbf{f}$ ) A representative picture of pseudopod formation in macrophages in testes of $\mathrm{CdCl}_{2}$-treated rats. Bar, $10 \mu \mathrm{m}$.

germ cells did not exhibit any notable levels of the bilirubin generation under both control and $\mathrm{CdCl}_{2^{-}}$ stimulated conditions. As seen in Figure 4c, ZnPP, an HO blocker, attenuated the bilirubin immunoreactivities in Leydig cells. Since $\mathrm{ZnPP}$ might affect function of other enzymes besides $\mathrm{HO}$, such as soluble guanylate cyclase $(22,23)$, we examined effects of CuPP, a metalloprotoporphyrin that does not block $\mathrm{HO}$ as a negative control reagent. This reagent did not suppress the $\mathrm{CdCl}_{2}$-induced increase in bilirubin-IX $\alpha$ immunoreactivities (Figure 4d), suggesting that inhibitory effects of $\mathrm{ZnPP}$ is $\mathrm{HO}$ dependent. We also confirmed that the present dose of $\mathrm{ZnPP}$ for the HO blockade could sufficiently block the microsomal HO activities in the testicular samples, while the same dose of CuPP did not change the activities (data not shown). The $\mathrm{CdCl}_{2}$-induced and HO-dependent elevation of the bilirubin generation appeared to coincide with reduced amounts of intact cytochrome P450 in the testicular microsome. The 12-hour $\mathrm{CdCl}_{2}$ treatment caused approximately a $40 \%$ reduction of the enzyme contents as compared with the control
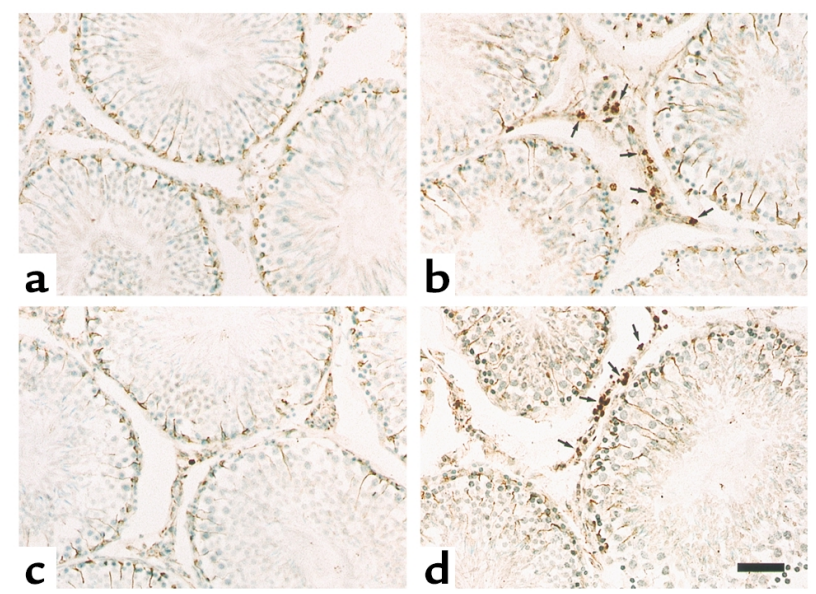

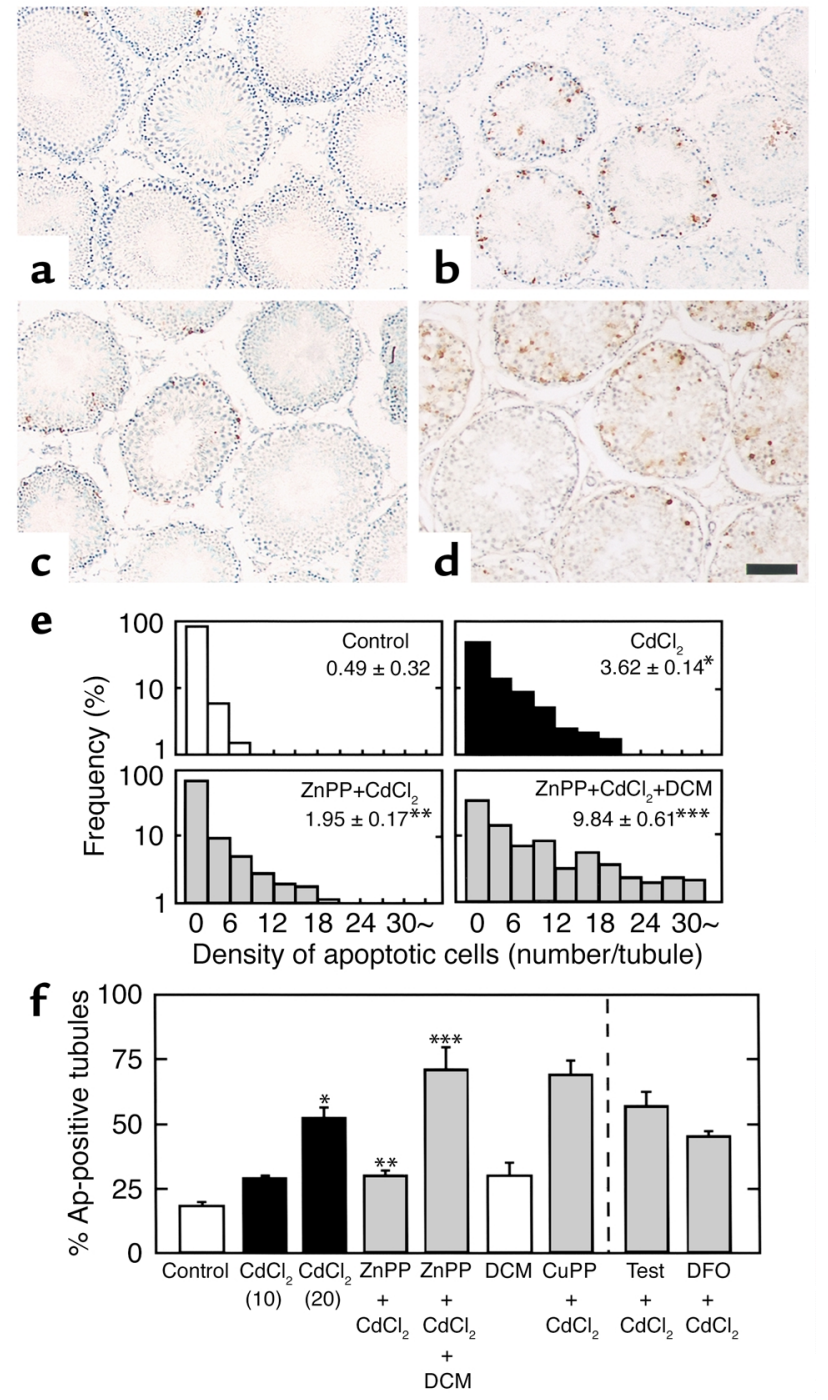

$(15.5 \pm 0.4$ vs. $26.2 \pm 2.8 \mathrm{pmol} / \mathrm{mg}$ microsomal protein; mean \pm SE of four experiments; $P<0.05$ ), while the group pretreated with $\mathrm{ZnPP}$ did not exhibit such a significant reduction $(20.5 \pm 1.8 \mathrm{pmol} / \mathrm{mg}$ microsomal protein, $n=4)$. These results suggest that the increase in $\mathrm{HO}$ activities plays a role in the $\mathrm{CdCl}_{2}$-induced reduction of microsomal contents of functionally intact cytochrome $\mathrm{P} 450$, at least in part.

$\mathrm{CO}$ generated by $\mathrm{CdCl}_{2}$-induced $\mathrm{HO}$ activity induces apoptosis of germ cells. Results shown in Figure 4 led us to examine whether the $\mathrm{CdCl}_{2}$-elicited $\mathrm{HO}-1$ induction could play an inhibitory or stimulatory role in apoptosis of testicular germ cells. As seen in Figure 5, the TUNEL staining in the 12 -hour $\mathrm{CdCl}_{2}$-treated groups confirmed that the initial apoptotic changes occur mostly in germ cells distributing in peritubular regions, being consistent with results shown in Figure 3. Furthermore, the severity of apoptotic changes appeared to vary among individual seminiferous tubules. The $\mathrm{CdCl}_{2}$-induced apoptotic changes appeared to be attenuated by pretreatment with $\mathrm{ZnPP}$, as shown in Figure $5 \mathrm{c}$. We then examined effects of supplementation of

\section{Figure 5}

Demonstration of apoptotic cells in seminiferous tubules in the 12-hour $\mathrm{CdCl}_{2}$-treated rats assessed by in situ 3' end labeling of single-strand DNA. ( $\mathbf{a}$ and $\mathbf{b}$ ) Representative pictures of testes in the $\mathrm{CdCl}_{2}$-untreated and -treated groups, respectively. Note that peritubular germ cells constitute a major cellular component displaying apoptosis. (c) Effects of pretreatment with $\mathrm{ZnPP}$ on the $\mathrm{CdCl}_{2}$-elicited apoptosis of germ cells. (d) Restoration of $\mathrm{CdCl}_{2}$-induced germ cell apoptosis by $\mathrm{CO}$ supplementation with dichloromethane under blockade of the $\mathrm{HO}$ reaction by ZnPP. Bar, $100 \mu \mathrm{m}$. (e) Differences in histograms showing the density of apoptotic cells in individual seminiferous tubules among groups. Data were indicated by relative frequency (\%) as a function of the density of apoptotic cells per a single tubule. (f) Differences in percentages of TUNEL-positive seminiferous tubules (percentage of apoptosis-positive tubules) among groups. Two different doses of $\mathrm{CdCl}_{2}$ (10 and $20 \mu \mathrm{mol} / \mathrm{kg}$ ) were examined. Effects of other interventions were examined in rats treated with $20 \mu \mathrm{mol} / \mathrm{kg} \mathrm{CdCl}$. Tubules containing at least one TUNELpositive cell were considered to be positive in this analysis. Bars represent the mean $\pm \mathrm{SE}$ of measurements from four to eight separate experiments. In an individual experiment, at least 200 different tubules were examined to calculate a single data set. DCM, dichloromethane; Test, testosterone, DFO, desferrioxamine. ${ }^{*} P<0.05$ as compared with the control. ${ }^{* *} P<0.05$ as compared with the group treated with $20 \mu \mathrm{mol} / \mathrm{kg} \mathrm{CdCl} 2 .{ }^{* * *} P<0.05$ as compared with the group treated with $\mathrm{ZnPP}+\mathrm{CdCl}_{2}$.

CO by administering dichloromethane. A single dose of dichloromethane at $6 \mathrm{mmol} / \mathrm{kg}$ in the control rats markedly increased percentages of $\mathrm{HbCO}$ in blood samples: the values peaked at 3 hours $(23.7 \% \pm 3.4 \%$ vs. $1.9 \% \pm 1.0 \%$, mean \pm SE of three rats, $P<0.05)$ and were kept at significantly greater levels until 6 hours $(10.6 \% \pm 2.8 \%$ vs. $2.6 \% \pm 0.3 \%$, mean \pm SE of three rats, $P<0.05)$. These results suggested that the protocol for administration of dichloromethane twice at 6-hour intervals stimulated endogenous $\mathrm{CO}$ generation for at least 12 hours until the start of tissue sampling. As seen in Figure 5d, the current protocol for CO supplementation markedly restored $\mathrm{CdCl}_{2}$-induced apoptosis of the germ cells even under blockade of $\mathrm{HO}$ by $\mathrm{ZnPP}$.

Differences in the magnitude of apoptosis among the groups were examined by calculating both density of TUNEL-positive germ cells among individual seminiferous tubules and percentages of the TUNELpositive tubules. The $\mathrm{CdCl}_{2}$ administration at 20 $\mu \mathrm{mol} / \mathrm{kg}$ increased both the density of apoptotic cells per a single tubule and percentages of apoptosis-positive tubules (Figure 5, e and f), while its dose of 10 $\mu \mathrm{mol} / \mathrm{kg}$ did not cause a significant change. As seen in Figure 5f, the apoptotic change elicited by 20 $\mu \mathrm{mol} / \mathrm{kg} \mathrm{CdCl}{ }_{2}$ was inhibited significantly by blocking $\mathrm{HO}$ with $\mathrm{ZnPP}$ and restored by donating $\mathrm{CO}$ with administration of dichloromethane. Furthermore, the present protocol for the $\mathrm{CO}$ supplementation by itself did not cause any notable apoptosis, despite the fact that $\mathrm{HbCO}$ levels markedly increased during the 12hour period for the dichloromethane supplementation. On the other hand, CuPP did not suppress the $\mathrm{CdCl}_{2}$-induced apoptosis. Differences in percentages of apoptosis-positive tubules among the groups were 


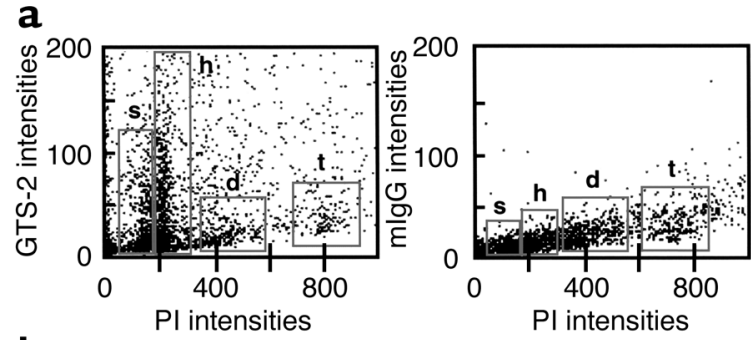

b
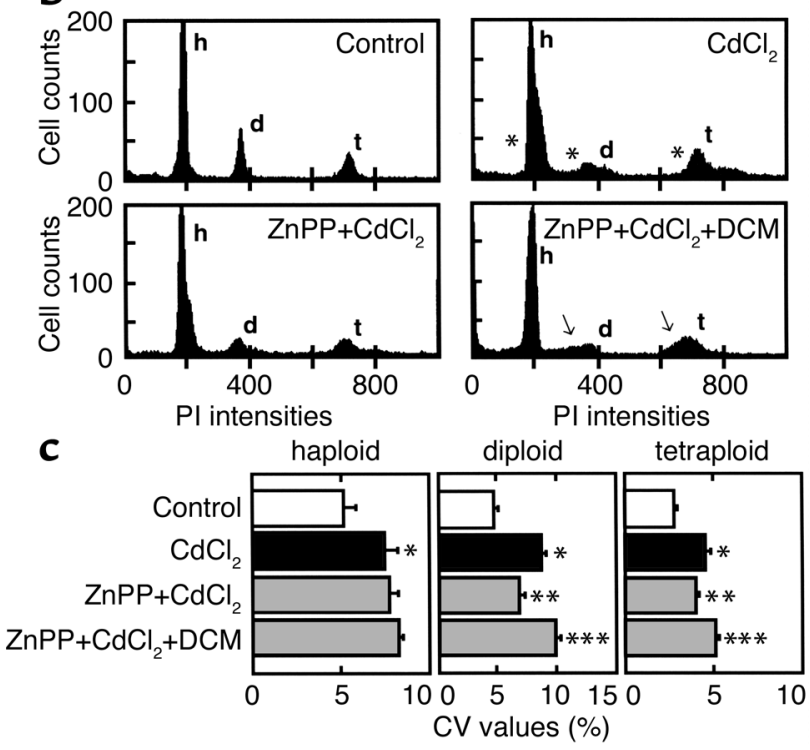

unlikely to result from possible heterogeneity of the density of testicular cells in the areas observed, since the density of Sertoli cells, i.e., Ad4BP-positive peritubular cells, in the same regions did not differ significantly among the groups; the relative percentage densities of Sertoli cells versus controls $(100 \% \pm 4 \%)$ were $110 \% \pm 5 \%, 108 \% \pm 5 \%$, and $102 \% \pm 8 \%$ in groups treated with $\mathrm{CdCl}_{2}, \mathrm{ZnPP}+\mathrm{CdCl}_{2}$, and $\mathrm{ZnPP}+\mathrm{CdCl}_{2}$ + dichloromethane, respectively (mean \pm SE of data collected from four to five separate rats). These data also convinced us that the viability of Sertoli cells was not altered by the $\mathrm{CdCl}_{2}$ exposure under the current experimental conditions. The increased HO activity could degrade the prosthetic heme group for steroidogenic cytochromes $\mathrm{P} 450$ and provide divalent iron as a cytotoxic factor. Thus, effects of supplementation of testosterone or iron chelation by desferrioxamine mesilate were examined, but without any notable suppression of apoptosis (Figure $5 f$ ). These results collectively suggest that the $\mathrm{CdCl}_{2}$-induced apoptosis of testicular germ cells is an event mediated by $\mathrm{CO}$ derived from inducible $\mathrm{HO}$.

\section{Figure 7}

Immunohistochemical analyses of $\mathrm{CdCl}_{2}$-induced alterations in expression of Fas and FasL. (a and $\mathbf{b}$ ) Representative pictures for Fas immunoreactivities. (c and d) Representative pictures for FasL immunoreactivities in the control and 12-hour $\mathrm{CdCl}_{2}$-treated groups, respectively. The dose of $\mathrm{CdCl}_{2}$ is $20 \mu \mathrm{mol} / \mathrm{kg}$. Bar, $50 \mu \mathrm{m}$.

\section{Figure 6}

$\mathrm{CdCl}_{2}$-induced disruption of cell phase-specific DNA contents in testicular germ cells and effects of the $\mathrm{HO}$ blockade by ZnPP and $\mathrm{CO}$ supplementation by dichloromethane (DCM). (a) Characterization of HO-2 expression in testicular germ cells. s, subhaploid; h, haploid; $\mathrm{d}$, diploid; $\mathrm{t}$, tetraploid. Note that the cells in subgroups $\mathrm{s}$ and $\mathrm{h}$ exhibited greater expression of $\mathrm{HO}-2$ than those in $\mathrm{d}$ and $\mathrm{t}$. The right panel exhibits two-color dot-plot analysis using mouse $\lg G$ as a negative control. (b) Differences in histogram showing DNA contents in specific cell phases among groups. The ratio of DNA contents as judged by $\mathrm{PI}$ fluorescence is 1:2:4 for subgroups $h, d$, and $t$, respectively. Note that variations of DNA contents become evident in the $\mathrm{CdCl}_{2}$-treated group (asterisks in $\mathbf{b}$ ). Such variations of DNA contents were also evident in the $\mathrm{ZnPP}+\mathrm{CdCl}_{2}$-treated group supplemented with DCM (arrows in b). (c) Differences in CV values of each cell population among groups. ${ }^{*} P<0.05$ as compared with the control. Data indicate mean \pm SE of six to seven separate experiments for each group. ${ }^{* *} P<0.05$ as compared with the $\mathrm{CdCl}_{2}$-treated group. ${ }^{* * *} P<0.05$ as compared with the group treated with $\mathrm{ZnPP}$ and $\mathrm{CdCl}_{2}$.

\section{Diploid and tetraploid germ cells exbibit CO-mediated apop-} tosis. Cell phase-specific alterations and variations of DNA contents were determined in individual germ cells by FACS analyses in the 24-hour $\mathrm{CdCl}_{2}$-treated rats. As seen in the two-color dot-plot diagrams (Figure 6a), three main populations of the cells expressing distinct levels of HO-2 protein were identified as a function of their DNA contents, denoting haploid (h), diploid (d), and tetraploid $(t)$, with increasing PI fluorescence. With careful evaluation of the haploid peak, the small cell population with moderate HO-2 expression with the smallest amounts of DNA (by PI fluorescence) was notable and corresponded to elongated spermatids and spermatozoa, being designated as subhaploid (s). Among these subgroups, the cells in groups $\mathrm{s}$ and $\mathrm{h}$ exhibited greater expression of $\mathrm{HO}-2$ than those in $\mathrm{d}$ and t. These results were in good agreement with immunohistochemistry showing GTS-2 immunoreactivities in relatively differentiated cells in centritubular regions.

As seen in the control data in Figure 6b, haploid, diploid, and tetraploid cells constituted the specific ratio of DNA contents, such as 1:2:4, respectively, peaking with small SDs. The germ cells collected from the $\mathrm{CdCl}_{2}$-treated rats also displayed three peaks, but with

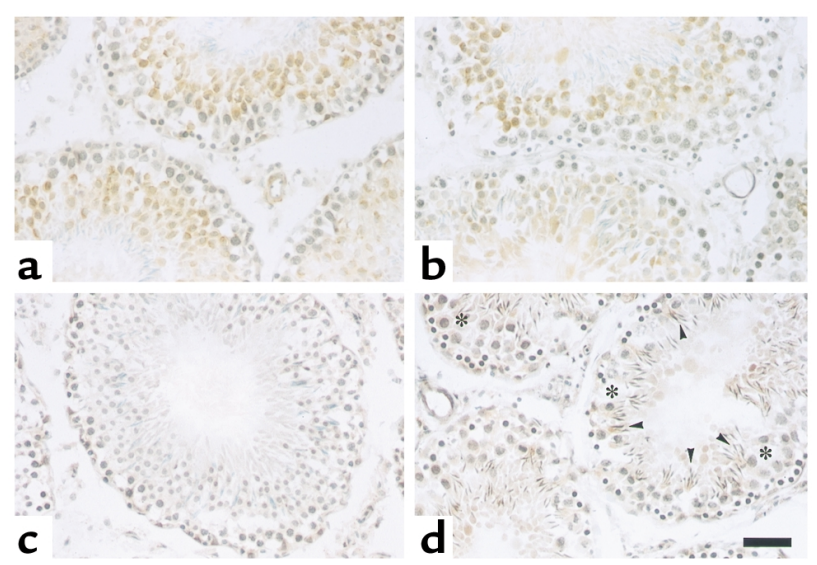



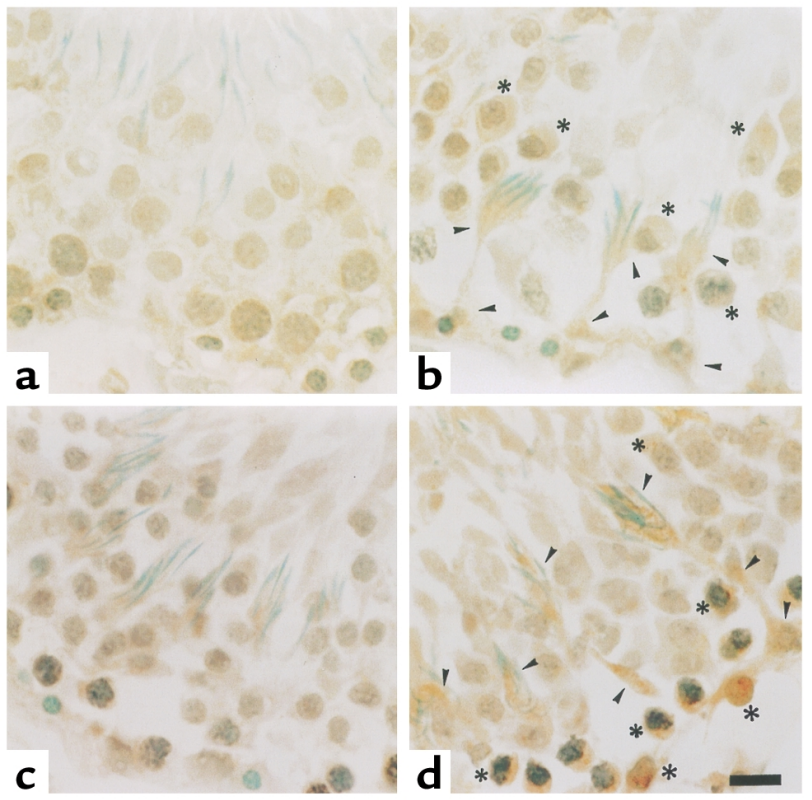

enlarged widths of histograms (asterisks in Figure 6b), indicating enhanced heterogeneity of DNA contents. Among them, diploid cells markedly reduced the peak height upon $\mathrm{CdCl}_{2}$ exposure. When pretreated with $\mathrm{ZnPP}$ in the absence or presence of dichloromethane, the heights and SD values of each cell type appeared to change notably (arrows in Figure 6b). We thus compared differences in $\mathrm{CV}$ values among groups. The $\mathrm{CdCl}_{2}$ exposure significantly increased $\mathrm{CV}$ values of haploid, diploid, and tetraploid cells (Figure $6 \mathrm{c}$ ). The $\mathrm{HO}$ blockade by $\mathrm{ZnPP}$ attenuated the $\mathrm{CdCl}_{2}$-elicited elevation of $\mathrm{CV}$ values preferentially in diploid and tetraploid cells, but not in haploid cells. On the other hand, the CuPP administration did not alter these $\mathrm{CdCl}_{2}$-induced changes in $\mathrm{CV}$ values (data not shown). Furthermore, supplementation of dichloromethane, a $\mathrm{CO}$ donor, significantly restored the ZnPP-induced CV attenuation in these cell types. As shown in Figure 3, the $\mathrm{CdCl}_{2}$-induced apoptosis appeared to occur in germ cells in peritubular regions involving spermatogonia (diploid) and primary spermatocytes (tetraploid) rather than in Sertoli cells, as judged by the fact that Ad4BP-positive cells did not exhibit nuclear fragmen-

\section{Figure 9}

Overexpression of FasL in testicular diploid cells elicited by $\mathrm{CdCl}_{2}$. (a) Western blot analyses in whole testicular lysates using the anti-FasL $\mathrm{Ab}$ sc-834. Densitometric analyses indicate relative gray levels versus controls (mean $\pm \mathrm{SE}$ of four separate experiments). $\mathrm{CdCl}_{2}$ at 20 $\mu \mathrm{mol} / \mathrm{kg}$ was administered 12 hours before experiments. ${ }^{*} P \leq 0.05$ as compared with the control. (b) Dual-color analyses between DNA contents (PI) and FasL expression (sc-834). (c) Histograms showing alterations in the FasL expression in the diploid cells among groups. A representative set of three experiments was shown. Histograms with gray backgrounds indicate controls stained by rabbit IgG. Note that the $\mathrm{CdCl}_{2}$ exposure markedly upregulates FasL expression, and the event was attenuated by $\mathrm{ZnPP}$ and restored by $\mathrm{CO}$ donation with dichloromethane (asterisks).

\section{Figure 8}

Effects of $\mathrm{ZnPP}$ and dichloromethane on the $\mathrm{CdCl}_{2}$-induced alterations in the FasL expression in peritubular regions. (a and $\mathbf{b}$ ) Representative pictures in the control and $\mathrm{CdCl}_{2}$-treated groups, respectively. (c and d) Representative pictures of the $\mathrm{CdCl}_{2}+\mathrm{ZnPP}$-treated groups in the absence and presence of dichloromethane, respectively. Note that $\mathrm{CdCl}_{2}$ increases FasL-associated immunoreactivities in Sertoli cells (arrowheads in b) and peritubular germ cells (asterisks in b). Such changes were also reproduced in the $\mathrm{ZnPP}+\mathrm{CdCl}_{2}$-treated group supplemented with dichloromethane (arrowheads and asterisks in d). The dose of $\mathrm{CdCl}_{2}$ is $20 \mu \mathrm{mol} / \mathrm{kg}$. Bar, $10 \mu \mathrm{m}$.

tation and condensation. Since apoptosis accounts for a factor causing increased CV values (19), these results collectively suggest that spermatogonia and primary spermatocytes exhibit CO-mediated apoptosis in the current experimental model. On the other hand, an increase in CV values in haploid germ cells was unlikely to result from apoptosis, but presumably from nonapoptotic damage of the cells by $\mathrm{CdCl}_{2}$, inasmuch as apoptosis could hardly be observed in central regions of tubules under current experimental conditions.

$\mathrm{CO}$ appears to serve as a factor responsible for triggering apoptosis. Fas-mediated signal transduction was shown previously to participate in apoptosis of testicular germ cells and to be implicated in maintaining immune privilege in testes $(17,24)$. Considering this fact, we attempted to examine immunohistochemically if

$\mathbf{a}$
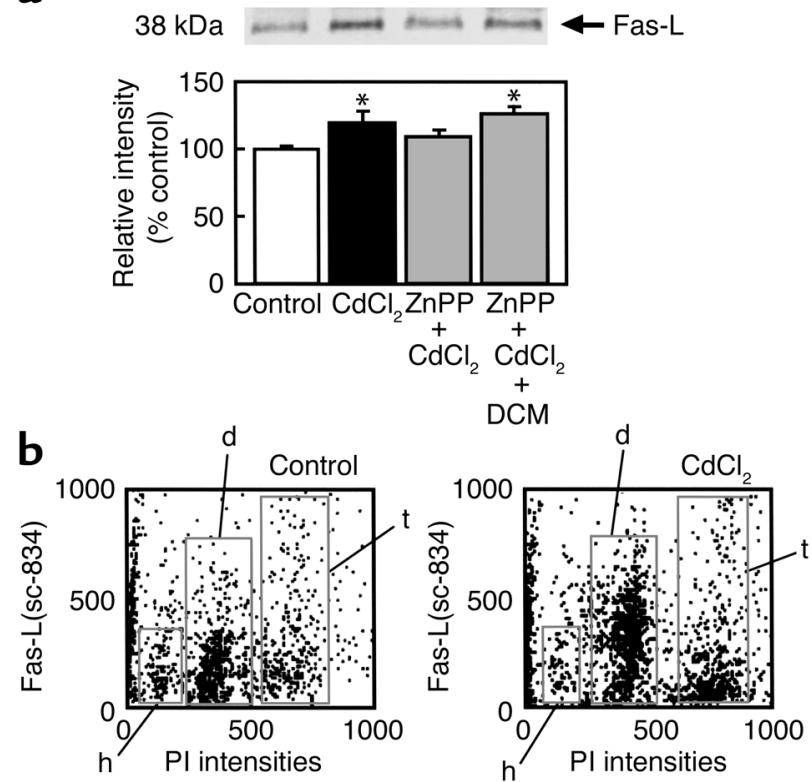

C

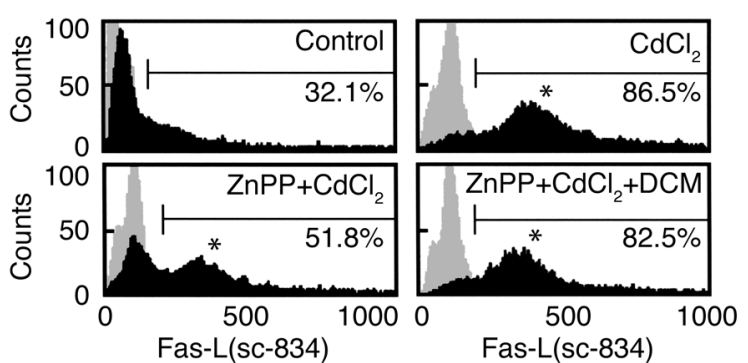


$\mathrm{CdCl}_{2}$ could cause alterations in expression of Fas and FasL in testes. As shown in Figure 7a, Fas was expressed in a majority of germ cells in the control, and the $\mathrm{CdCl}_{2}$ exposure did not greatly change such an immunostaining pattern (Figure 7b). On the other hand, FasLassociated immunoreactivities were faintly observed over germ cells in peritubular regions (Figure 7c), supporting recent results showing their FasL expression (25). When exposed to $\mathrm{CdCl}_{2}$, however, the FasL immunoreactivities became enhanced in different types of cells in the peritubular regions as indicated by arrowheads and asterisks in Figure 7d. Careful observation by high magnification in the peritubular regions of the $\mathrm{CdCl}_{2}$-untreated and -treated (Figure 8, a and b) testes revealed that Sertoli cells (arrowheads) and premeiotic germ cells, including spermatocytes and spermatogonia (asterisks), were responsible for the $\mathrm{CdCl}_{2}$-induced enhancement of FasL immunoreactivities. It should be noted that such an enhancement of FasL staining appeared to be attenuated by blockade of $\mathrm{HO}$ by ZnPP (Figure 8c). Furthermore, CO supplementation by dichloromethane caused a restoration of FasL immunoreactivities in both Sertoli cells (arrowheads in Figure 8d) and germ cells (asterisks in Figure 8d), even under the HO-inhibiting conditions.

Such cell phase-specific alterations in the FasL expression upon $\mathrm{CdCl}_{2}$ exposure were confirmed by FACS analyses of the dispersed testicular cells. Western blot analyses using lysates of the whole testes (Figure 9a) revealed the stimulus-elicited increase in the FasL overexpression. This increase was partially attenuated by $\mathrm{ZnPP}$ and was restored significantly with $\mathrm{CO}$ donation by dichloromethane, although the change appeared small when assessed in the whole organ. Considering the immunohistochemical analyses that alterations in the FasL expression seemed to be cell type-specific events, dual-color FACS analyses using PI (DNA contents) and sc-834 (FasL) were carried out. As seen in Figure $9 \mathrm{~b}$, the $\mathrm{CdCl}_{2}$-induced overexpression of FasL occurred mainly in diploid cells and partially in tetraploid cells. On the other hand, postmeiotic cells such as haploid cells did not show any notable overexpression of FasL. Further examination of the diploid cells gated with their DNA contents showed that greater than $80 \%$ of these cells exhibited a marked elevation of the FasL expression. The $\mathrm{CdCl}_{2-}$ elicited elevation of the FasL expression was attenuated markedly by $\mathrm{ZnPP}$ and restored almost completely by CO supplementation with dichloromethane (asterisks in histograms of Figure 9c). These results were in agreement with aforementioned results in immunohistochemistry and suggest that $\mathrm{CO}$ plays a role in $\mathrm{CdCl}_{2}$-induced alterations in FasL expression in both Sertoli cells and germ cells.

\section{Discussion}

The testis is a major organ that abundantly expresses $\mathrm{HO}$ activities, though cell types expressing the HO isozymes and the alterations in their activities under stress conditions have yet to be well characterized. This study provided evidence that $\mathrm{HO}-1$ and $\mathrm{HO}-2$ occur in distinct cell types in testes under control and stress conditions. Under unstimulated control states, HO-1 is expressed in interstitial macrophages and Sertoli cells, whereas it was expressed in germ cells and Leydig cells little, if at all. On the other hand, HO-2 occurs in subpopulation of the matured germ cells and their residual bodies: this finding was also confirmed by FACS analyses of these cells in vitro. Activities and distribution of the isozymes are dramatically altered as a function of time after exposure to $\mathrm{CdCl}_{2}$. $\mathrm{HO}-1$ is markedly induced in Leydig cells, while HO-2 is reduced as a result of the stressor-induced reduction of germ cells. Such an inverse relationship between the two isozymes was also well demonstrated by our novel method to determine the isozyme-specific enzyme activities. The current results indicate that testis use Leydig cells as a sensor of metal stress and induces $\mathrm{HO}-1$, and a reduction of the testicular $\mathrm{HO}$ activities as a whole appears to result merely from the reduction of intact testicular germ cells that express HO-2. Previous studies showing that $\mathrm{CdCl}_{2}$ exposure did not increase but decrease total $\mathrm{HO}$ activities in the testis suggested that this organ might exhibit stress responses distinct from those in the liver and spleen (26), being obviously inconsistent with our results.

Another important finding in the current study is identification of cells responsible for actual degradation of heme in this HO-enriched organ. As judged by immunohistochemical localization of bilirubin-IX $\alpha$, the HO-derived end product of the degradation, Sertoli cells appeared to constitute a major cellular component responsible for $\mathrm{HO}$-mediated heme degradation, while Leydig cells displayed only small amounts of the product under unstimulated conditions. By contrast, upon exposure to $\mathrm{CdCl}_{2}$, Leydig cells exhibited marked bilirubin-IX $\alpha$-positive reactivities, while the change in Sertoli cells was not notable. It should be noted in both conditions that germ cells displayed few immunoreactivities of bilirubin-IX $\alpha$, despite considerable expression of HO-2 in these cells. Considering that generation of bilirubin-IX $\alpha$ occurs in parallel with $\mathrm{CO}$ production, these results suggest that Leydig cells constitute a major cellular component for active $\mathrm{HO}$ reaction and $\mathrm{CO}$ generation upon $\mathrm{CdCl}_{2}$ exposure.

Since P450 cytochrome monooxygenases are responsible for testosterone synthesis in the cells, the HO- 1 induction in the same cells could cause suppression of the activities of the monooxygenases. Multiple mechanisms should be taken into account. First, prosthetic heme molecules required for their catalytic activities are degraded by the $\mathrm{HO}-1$ induction in the same cell. Such a notion is well supported by observation in the current and previous studies that cadmium exposure significantly reduced testicular contents of microsomal cytochromes $\mathrm{P} 450$ (26). Second, both cytochromes P450 and HO share NADPH as an electron donor, and the HO-1 
induction could decrease the reductant available for the testosterone synthesis in Leydig cells. Third, CO generated by HO- 1 in Leydig cells could be bound directly to the prosthetic heme of $\mathrm{P} 450$ cytochromes and thereby inhibit testosterone synthesis in the cells. Such a topographic correlation between microsomal cytochromes P450s and HO-1 induction shed light on a crucial role of the cell-specific heme degradation in testicular steroidogenesis and is also consistent with previous observation that the $\mathrm{CdCl}_{2}$ administration actually reduced testosterone production in Leydig cells (27).

Current observation that the stress-inducible $\mathrm{CO}$ generation occurs preferentially in Leydig cells raised an important question as to mechanisms through which the stress response occurring in the interstitial space (e.g., Leydig cells) could transfer signal(s) for apoptosis of germ cells in the seminiferous tubules, considering the presence of the blood-testicular barrier that limits access of signaling molecules from the interstitium into the tubules (1). CO appears to serve as such a barrier-permeable signaling molecules for the germ cell apoptosis. Extrapolation of previous studies provided several mechanisms for cell death triggered by HO-1. First, the HO-1 induction could reduce cytochrome P450 monooxygenases in Leydig cells and secondarily suppress synthesis of testosterone required for spermatogenesis. However, as judged so far by negative effects of exogenous supplementation of testosterone, a shortage of the hormone synthesis is unlikely to play a crucial role directly in the germ cell apoptosis at the initial phase of the $\mathrm{CdCl}_{2}$ toxicity. Second, divalent iron, another $\mathrm{HO}$ product, could cause the Fenton reaction that results in propagation of oxygen radical toxicity when it is generated in excess. However, this scenario appears to be implausible, since administration of the iron chelator did not attenuate the apoptosis in the $\mathrm{CdCl}_{2}$-exposed testes. A possible secondary effect of $\mathrm{CO}$ on downregulation of the testosterone synthesis could also be excluded because of the ineffectiveness of the hormone supplementation.

Of greatest importance is the direct effect of $\mathrm{CO}$ on germ cell apoptosis. Recent observations show that $\mathrm{CO}$ is able to trigger apoptosis at nanomolar concentrations in certain types of cells, such as vascular endothelial cells in culture (28), though the gas-reception mechanisms are still unknown. Restoration effects of CO supplementation by dichloromethane on germ cell apoptosis fully support a concept that $\mathrm{CO}$ overproduced through the HO-1 reaction in Leydig cells could trigger germ cell apoptosis. The current immunohistochemical analyses using Ab's against Fas and FasL led us to consider that at least two pathways could be involved in mechanisms through which $\mathrm{CO}$ derived from Leydig cells triggers apoptosis of spermatogonia and primary spermatocytes, Sertoli cell-dependent and -independent pathways. Under the current experimental conditions, Sertoli cells neither exhibited apoptosis nor displayed loss of viability, as judged by the density of Ad4BP-positive cells in seminiferous tubules. These cells notably upregulated FasL expression in response to the $\mathrm{CdCl}_{2}$ exposure, while the response was attenuated by the HO blockade and restored by the $\mathrm{CO}$ donation. These results suggest that Sertoli cells actively respond to $\mathrm{CO}$ without altering their viability for triggering Fas/FasL-mediated apoptosis in germ cells adjacent to them (e.g., spermatogonia and primary spermatocytes). On the other hand, the present study did not exclude a possibility that CO generated in Leydig cells could directly stimulate germ cell apoptosis, inasmuch as the $\mathrm{CdCl}_{2}$ exposure as well as dichloromethane supplementation under the HO blockade causes a notable increase in FasL immunoreactivities in spermatogonia and/or primary spermatocytes, as seen in Figure 8. Such an apoptogenic effect of stressinduced $\mathrm{CO}$ deserves further studies given the evidence for the gas-reception mechanisms at peritubular regions of seminiferous tubules involving Sertoli cells and/or germ cells as the effector apparatus.

Finally, the present results showing HO-1-mediated and CO-dependent apoptosis of premeiotic germ cells under early differentiation phases (e.g., spermatogonia and primary spermatocytes) led us to inquire whether this event is beneficial or detrimental for homeostasis of spermatogenesis. It has well been recognized that spermatogenesis is a dynamic process of germ cell proliferation and differentiation controlled by endocrine and, potentially, paracrine factors derived from interstitial cells (1). Overproliferation of early germ cells is modified normally and continuously by selective programmed cell death, limiting the number of matured germ cells (29). Considering these facets, it is not unreasonable to propose that Leydig cells use the HO-1-CO system to limit the number of early germ cells through apoptosis and thereby contribute to a quality control of spermatogenesis under stress conditions. At the same time, the current study raised a clinically important question as to whether such a CO-mediated mechanism for apoptosis could be attributable to pathogenesis of clinical oligozoospermia caused by a variety of stressors; anticancer drugs (30), chronic and excess exposure to dichloromethane (31) and aromatic hydrocarbon derivatives (32) that could stimulate cytochrome P450derived $\mathrm{CO}$, and cryptorchidism, which is known to induce HO-1 in testes (33), are involved in such stimuli. Our preliminary experiments in rats have shown that administration of cis-diaminedichloroplatinum (cisplatin), a tumoricidal reagent causing oligozoospermia, causes a marked induction of HO-1 in both Leydig cells and Sertoli cells, while cryptorchidism leads to the induction preferentially in Sertoli cells (N. Ozawa and M. Suematsu, unpublished observation). These results led us to hypothesize that testes could properly use both types of cells to execute CO-mediated regulation of apoptosis under different stressors. Further investigation will be necessary to address whether such a mechanism for apoptotic control of spermatogenesis is actually executed under aforementioned disease conditions. 


\section{Acknowledgments}

The authors thank Hitomi Irisawa and Mieko Kondo for their expert technical support in immunohistochemistry and manuscript preparation. This study was supported by Advanced Medical Technology in Health Sciences Research Grants from Ministry of Health and Welfare in Japan.

1. Weinbauer, G.F., Gromoll, J., Simoni, M., and Nieschlag, E. 2000. Physiology of testicular function. In Andrology. E. Nieschlag and H.M. Behre, editors. Springer. Berlin, Germany. 23-61.

2. Rowe, P.J., Comhaire, F.H., Hargreave, T.B., and Mahmoud, A.M.A. 2000 History-taking. In WHO manual for the standardized investigation, diagnosis and management of the infertile male. Cambridge University Press. New York, New York, USA. 5-16.

3. Shikone, T., Billig, H., and Hsueh, A.J. 1994. Experimentally induced cryptorchidism increases apoptosis in rat testis. Biol. Reprod. 51:865-872.

4. Richburg, J.H. 2000. The relevance of spontaneous- and chemicallyinduced alterations in testicular germ cell apoptosis to toxicology. Toxicol. Lett. 112:79-86.

5. Maines, M.D. 1988. Heme oxygenase: function, multiplicity, regulatory mechanisms, and clinical applications. FASEB J. 2:2557-2568.

6. Trakshel, G.M., Kutty, R.K., and Maines, M.D. 1986. Purification and characterization of the major constitutive form of testicular heme oxygenase. The noninducible isoform. J. Biol. Chem. 261:11131-11137.

7. Chia, S.E., Xu, B., Ong, C.N., Tsakok, F.M., and Lee, S.T. 1994. Effect of cadmium and cigarette smoking on human semen quality. Int. J. Fertil. Menopausal. Stud. 39:292-298.

8. Kim, Y.C. 1997. Dichloromethane potentiation of carbon tetrachloride hepatotoxicity in rats. Fundam. Appl. Toxicol. 35:138-141.

9. Jiang, Y., Kuo, C.L., Pernecky, S.J., and Piper, W.N. 1998. The detection of cytochrome P450 2E1 and its catalytic activity in rat testis. Biochem. Biophys. Res. Commun. 246:578-583.

10. Scott, C.A., et al. 1996. Effects of cis-platinum and luteinizing hormone releasing hormone analogues on rat spermatogenesis. A morphologic and flow cytometric study. Anal. Quant. Cytol. Histol. 18:361-373.

11. Goda, N., et al. 1998. Distribution of heme oxygenase isoforms in rat liver. Topographic basis for carbon monoxide-mediated microvascular relaxation. J. Clin. Invest. 101:604-612.

12. Makino, N., et al. 2001. Altered expression of heme oxygenase- 1 in the livers of patients with portal hypertensive diseases. Hepatology. 33:32-42.

13. Hatano, O., et al. 1994. Sex-dependent expression of a transcription factor, Ad4BP, regulating steroidogenic P-450 genes in the gonads during prenatal and postnatal rat development. Development. 120:2787-2797.

14. Nakayama, M., et al. 2001. Increased expression of heme oxygenase- 1 and bilirubin accumulation in foam cells of rabbit atherosclerotic lesions. Arterioscler. Thromb. Vasc. Biol. 21:1373-1377.

15. Kyokane, T., et al. 2001. Carbon monoxide from heme catabolism pro- tects against hepatobiliary dysfunction in endotoxin-treated rat liver. Gastroenterology. 120:1227-1240.

16. Omura, T., and Sato R. 1964. The carbon monoxide-binding pigment of liver microsome. J. Biol. Chem. 239:2370-2378.

17. Lee, J., Richburg, J.H., Younkin, S.C., and Boekelheide, K. 1997. The Fas system is a key regulator of germ cell apoptosis in the testis. Endocrinology. 138:2081-2088.

18. Kiener, P.A., et al. 1997. Human monocyte cells contain high levels of intracellular Fas ligand. J. Immunol. 159: 1594-1598.

19. Darzynkiewicz, Z., et al. 1997. Cytometry in cell necrobiology: analysis of apoptosis and accidental cell death (necrosis). Cytometry. 27:1-20.

20. Rabinovitch, P.S. 1993. Practical considerations for DNA content and cell cycle analysis. In Clinical flow cytometry. K.D. Bauer, R.E. Duque, and T. Vincent Shankey, editors. Williams \& Wilkins. Baltimore, Maryland, USA. 117-142.

21. Ewing, J.F., and Maines, M.D. 1995. Distribution of constitutive (HO-2) and heat-inducible (HO-1) heme oxygenase isozymes in rat testes: HO-2 displays stage-specific expression in germ cells. Endocrinology. 136:2294-2302.

22. Agarwal, A., and Nick, H.S. 2000. Renal response to tissue injury: lessons from heme oxygenase-1 gene ablation and expression. J. Am. Soc. Nephrol. 11:965-973.

23. Hayashi, S., et al. 1999. Induction of heme oxygenase-1 suppresses venular leukocyte adhesion elicited by oxidative stress: role of bilirubin generated by the enzyme. Circ. Res. 85: 663-671.

24. Bellgrau, D., et al. 1995. A role for CD95 ligand in preventing graft rejection. Nature. 377:630-632.

25. D'Alessio, A., et al. 2001. Testicular FasL is expressed by sperm cells. Proc. Natl. Acad. Sci. USA. 98:3316-3321.

26. Maines, M.D., Chung, A.S., and Kutty, R.K. 1982. The inhibition of testicular heme oxygenase activity by cadmium. A novel cellular response. J. Biol. Chem. 257:14116-14121.

27. Laskey, J.W., and Phelps, P.V. 1991. Effect of cadmium and other metal cations on in vitro Leydig cell testosterone production. Toxicol. Appl. Pharmacol. 108:296-306.

28. Thom, S.R., Fisher, D., Xu, Y.A., Notarfrancesco, K., and Ischiropoulos, H. 2000. Adaptive responses and apoptosis in endothelial cells exposed to carbon monoxide. Proc. Natl. Acad. Sci. USA. 97:1305-1310.

29. Rodriguez, I., Ody, C., Araki, K., Garcia, I., and Vassalli, P. 1997. An early and massive wave of germinal cell apoptosis is required for the development of functional spermatogenesis. EMBO J. 16:2262-2270.

30. Stephenson, W.T., Poirier, S.M., Rubin, L., and Einhorn, L.H. 1995. Evaluation of reproductive capacity in germ cell tumor patients following treatment with cisplatin, etoposide, and bleomycin. J. Clin. Oncol. 13:2278-2280.

31. Kelly, M. 1988. Case reports of individuals with oligospermia and methylene chloride exposures. Reprod. Toxicol. 2:13-17.

32. Tielemans, E., et al. 1999. Occupationally related exposures and reduced semen quality: a case-control study. Fertil. Steril. 71:690-696.

33. Maines, M.D., and Ewing, J.F. 1996. Stress response of the rat testis: in situ hybridization and immunohistochemical analysis of heme oxygenase-1 (HSP32) induction by hyperthermia. Biol. Reprod. 54:1070-1079. 